\title{
Transitivity Analysis of the Short Story "The Happy Prince" Written by Oscar Wilde
}

\author{
Saeed Ahmad \\ Masters of Philosophy in Applied Linguistics \\ Department of Applied Linguistics \\ Government College University \\ Faisalabad, Pakistan \\ saeedahmad8844@gmail.com
}

\begin{abstract}
The present study investigates how the writer has established different characters in the story with the choice of linguistic features. For this purpose the data were taken from the famous short story titled "The Happy Prince" written by an Irish writer Oscar Wilde. The researcher applied the systemic functional linguistic theory presented by Halliday for transitivity analysis of the text. The text was manually analysed by the researcher. All the processes, participants and circumstances were recognized from the whole text. They were arranged in the form of tables and charts. The results were discussed in the qualitative method of research. The results show that three types of process i.e. material $(43.41 \%)$, relational $(20.26 \%)$ and verbal $(17.04 \%)$ were predominant in the whole text. The highest dominance of the material process shows that the writer has created dynamic and tangible actions in the text. Similarly circumstances of location i.e. place $(52 \%)$ and time (20\%) were dominant in the whole text. The significance of the study was also discussed in the educational perspective.
\end{abstract}

Keyword:Oscar Wilde, The Happy Prince,Short Story, Linguistic Features 
Introduction

It has been acknowledged that those who study and make the use of a language are keen on how they can get things done with language, how they can influence implications to develop and be comprehended through selections of words and linguistic properties. Bloor and Bloor assert that "when individuals make the use of language, their language acts create - develop meaning" (2004, p. 2). Kroger and Wood (2000, p. 4) believe that language is taken to be not just a device for description and a medium of association yet as a social practice, a method for getting things done. Gee (2005, p. 10) indeed, even claims that "language has a supernatural property: when we discourse or write, we outline what we need to state to fit the circumstance in which we are imparting. In any case, in the meantime, how we discourse or write makes that very circumstance." In other words, language shapes and fortifies behaviours and believes, then, is a medium for prompting characters, exercises, qualities, and philosophies.

The investigation of language is important to the point that, as Fairclough (1989, p. 2) states, "making the use of language is the most basic type of social behaviour" and we rely upon language in our open and private connection, deciding our associations with other people and the social establishments we occupy. For Halliday (1985, xiv), "a language is described as an arrangement of implications, joined by frames through which the implications can be acknowledged and answer the inquiry, "how are these implications communicated?" This puts the types of a language in an alternate point of view: as necessary chore, rather than as an end in themselves." It is from this point of view of language that systemic functional linguistics was produced by Halliday and his partners during the 1960s.

Fairclough claims that language "is a material type of belief system, and language is contributed by philosophy" (2001, p. 73). Social language or discourse isn't just illustrative however mediates in social change since "discourse adds to the creation and diversion of the relations, subjects... and questions which populate the social world" (p. 73). In other words, 
discourses are material impacts of ideology which additionally strongly affect forming our feeling of the real world. Making a similar point, Fowler makes the connection amongst discourse and ideology significantly clearer when he characterizes discourse as "socially and institutionally starting belief system, encoded in language" (1986, p. 42). Discourse is an approach to form and show belief systems, where "philosophy" can be characterized as the ordinary underestimated aggregate arrangement of presumptions and esteem frameworks that social gatherings share (Simpson, 1993).

In addition, ideologies are the fundamental and essential social ideas that mirror the points, significances and estimations of the social gathering (Wodak, 2001). Fairclough (2003) additionally focuses on that discourse is an intense vehicle in the development of social reality, a vehicle that shapes purposes of perspectives through predominant ideologies and builds the substances of living and being. In this sense, discourse is persuasively identified with the sociocultural and institutional settings. In the expressions of Fowler, "language gives names of classifications, thus sets limits and connections and discourse enables these names to be discourse and composed every now and again, so adding to the obvious reality and money of classifications" (1986, p. 94). Therefore, language and language ponder draw in a great deal of scholastic researchers from various orders to all the more likely comprehend contemporary society.

In view of this thought, in this paper, I will analyze the capacity of language as great social practice in the short story "The Happy Prince" distributed in 1988 by Oscar Wilde in the light of Halliday's theoretical system on transitivity. The point is to clear up the principle character's identity. 


\section{Literature Review}

Transitivity analysis has been generally used to comprehend the language of speakers and writers. It analyses the structure of sentences which are carried out by processes, the participants associated with these processes, and the circumstances in which processes and participants are included. Utilizing transitivity analysis, researchers have endeavoured to uncover that language structures can deliver certain meanings and ideas which are not constantly clear for users. In other words, the errand of practical analysis, especially transitivity analysis, is to find the connection amongst meaning and wordings that records for the association of linguistic feature in a writing. Therefore, the idea of transitivity has been utilized by various linguists to reveal more insight into the utilization of language in a scholarly content.

As a pioneer and researcher in transitivity analysis, Halliday's investigation of William Golding's The Inheritors is a persuasive illustration. Carter and Stockwell portray it as "one of the weighty analysis in stylistics" (1971, p. 19). In this analysis, Halliday brings up how understanding language structure, particularly transitivity, can help explain the significance in a scholarly content. As indicated by Halliday's theory, examples of transitivity, including processes, participants, and the circumstances, happen in the statements and sentences of a piece of writing. He states that "transitivity is the set of alternatives whereby the speaker encodes his experience and transitivity is extremely the foundation of the semantic association of experience" (p. 81).

Following the strategy for transitivity analysis created by Halliday, Yaghoobi (2009) makes a foundational analysis of news structures in two chose printed media, in particular Newsweek and the Kayhan International. By distinguishing processes and the part of participants associated with those processes, Yaghoobi's examination demonstrates that the portrayal of a similar news performers, Hizbullah and Israeli powers, by two unique and ideologically contradicted printed media, were inverse to each other. 
These transitivity examinations are only a couple among many, yet they are basic cases of how language designs, especially transitivity, can pass on the importance and belief system of an abstract content. They additionally include further measurements that have demonstrated helpful in expressive analysis. The functional sentence structure analysis of English helps readers comprehend human's associations in social settings and can be used to reveal ideological implications inside them. In the following part, the emphasis will be on clarifying the theory of transitivity.

A research base on the transitivity analysis was conducted by Asad Mehmood, Roshan Amber, Sobia Ameer and Rabia Faiz (2014). They have a primary research finding, that is inspect the capacity of language as helpful instrument in the short story "The Nightingale and the Rose" by Oscar Wilde in the light of Halliday's theoretical structure on transitivity. The point is to introduce two perspectives of adoration by means of two noteworthy characters. They utilize a content analysis method. They presume that the transitivity analysis of Wilde's short story The Nightingale and The Rose show how the activities are performed using material processes. We get a clearer thought from the verbal processes that portray the activities and in addition uncovering the circumstance and conditions. Furthermore this effect is strengthened by the social processes. The physical activities are featured through these processes with give an external perspective of the world depicted in the story.

Wahyu Dwi S (2010) led research to discover ideational which means in childrens melodies.

He takes childrens tunes Barney „Dancing furthermore, Singingee arrangement as the information. Other than the ideational implications, she too concerns the thematic improvement in the writings. The aftereffect of this research demonstrates that there are 115 provisions. The ideational significance found in the arrangement are fellowship, want, deference. The theme improvements utilized by the musician are emphasis and crisscross. 
There is a contrast between this research and this past examination. This past investigation is intented to locate the ideational significance and the theme improvement design. In any case, this research has the reason to locate the specific attributes of the mission statement with the goal that the reason for it very well may be figured it out.

(Zahoor \& Janjua, 2016) state that Transitivity analysis is the most broadly utilized system under Halliday's SFL. It has demonstrated to have a differing degree in content and talk analysis. Transitivity analysis can give an extensive phonetic confirmation to the perusers in regards to "who/what does what to whom/what?" in this way, to touch base at a superior comprehension of the characters in a scholarly content.

According to (Zahoor \& Janjua, 2016)The principle character in the tune "I am Malala" is a mysterious young lady whose voice echoes Malala's voice along these lines her character has been examined as an encapsulation of Malala. Examining the "processes" and the "participants" related with these processes, transitivity analysis of the melody uncovered that Malala is much the same as all the young ladies of her age - feeble, shy and uncouth. She isn't sufficiently solid to change the world via completing any solid material activity all alone.

The main power they can have is "the intensity of [their] discourse" (3a). In any case, their discourse too will be heard on the off chance that they talk in assembly, to speak alone will expect them to mask their character (7d) as "Malala" did by utilizing a nom de plume Makai in her questionable blog composing. Being "broken inside" Malala needs support and quality from others. She is just a voice, a dream, a fantasy, a desire and a motivation for others to go to bat for their rights. To make up for their young age and ladylike delicacy, she accepts also, advocates that all young ladies like her should be "more brilliant" (24), "shrewd" (29) and vocal. Malala's otherworldly and mental patience is a positive character characteristic featured in the melody that influenced her to withstand the abuse she needs to confront. It is 
fundamentally this ersatility on her part, being excessively for her age and sexual orientation that she has been depicted as a symbol for young ladies all around.

In the present study the researcher has also used the framework of transitivity analysis presented by Halliday to elaborate the characters in a literary discourse. The study however is typical in the sense that it aims to illuminate the description of the major characters in a short story titled

“The Happy Prince". The Happy Prince and Other Tales also sometimes called The Happy Prince and Other Stories is an accumulation of stories for kids by Oscar Wilde initially distributed in May 1888. It is most celebrated for The Happy Prince, the short story of a metal statue who gets to know a transitory swallow bird. Together, they convey bliss to others, in life and in addition in death. The story passes on a admiration for generosity, sympathy, love and majesty

Theory on Transitivity

Halliday described the systemic functional linguistics approach to discourse analysis which is based on the model of "language as a social semiotic". Language has a functional role and its use depends on needs to be accomplished. According to the Halliday's theory, language describes three basic types of meanings: ideational, interpersonal, and textual meanings

(1985). The ideational meaning (the clause as representation) describes the content meanings of the language and it includes our real world experience as well as our inner world experience.

Language is used often to talk about something or someone's action. Because of that the ideational meaning can also be called as experiential meaning which can be derived from the clause as representation. 
The social relations are created and maintained with the help of the interpersonal meanings of language. This aspect of language enables the individual to interrelate with other people. For this purpose the individual uses the expression of his own individuality. The interpersonal meaning of language describes the role of language user in his/her interrelations with the society and his/her attitude towards the others people. In language, a clause acts as an exchange and from this exchange comes the interpersonal meaning. We use language in order to make actions or demand something and generally the result comes in verbal or written form.

In the textual meaning of language associations between features of the text and elements in the situational context are created. This aspect of language discusses the way of text organization. In other words, the clause as message is used to obtain the textual meaning. The clause obtains its meaning or massage from its thematic construction. The message has two parts: theme and rheme. The theme of clause has been defined by Halliday and

Matthiesen in the following words: "starting point of the message: it is what the clause is going to be about" (2004, p. 64). It can be said that the theme is used to elaborate the clause in its context. The second part of the message is rheme. It makes extension and elaboration of the theme within the message. In this way the combination of theme and rheme elaborates the text orientation and its facts.

According to Halliday, these three kinds of meaning are necessary for performing the speech functions in the society.

Creating the ideational meaning can be made through major system called the system of transitivity which involves grammatical choice. In transitivity system, the process types are discussed. For the following research paper the system of transitivity has been chosen and all the grammatical aspects of the text have been analysed to produce fruitful results from the text.

Transitivity has been describes by Halliday in his book An Introduction to Functional Grammar, in the following words: 
It is a basic aspect of language that it makes possible for the human beings to create a mental picture of reality, to make a true picture of their outer and inner world experience. ...Our most powerful concept of reality is that it consists of "goings-on": of doing, happening, feeling, being. These goings-on are arranged in the semantic system of language, and described through the clausal grammar. This system is called the TRANSITIVITY SYSTEM. Transitivity identifies the various kinds of processes that are processed in the language and the constructions by which they are explained. (1985, p. 101)

Halliday established and developed the theoretical framework of transitivity. In transitivity we study how the meanings are produced and represented through the clauses. Different incidents and events and various types of processes are represented by the clauses and transitivity patterns in the clause. The main aim of transitivity system is to make it clear how the action is done and controlled by whom and on whom/what. Halliday's crucial and powerful semantic concept is transitivity. Ideational function of language is performed through it, therefore it is used as an important and powerful tool in the representational analysis of any literary text. In other words I can claim that different structures of transitivity will be required to produce various kinds of social, values, actions and structures.

Kress (1976) describes transitivity as the representation of meaning in language processes, and Simpson (1993) claims that the system of transitivity is used to elaborate the fact how a clause creates and represents meaning.

In other words, transitivity is used to show the fact how speakers/writers use language to encode their mental state and the representation of the world and how they express their experience of the world which is being occurred around them.

Halliday states that transitivity is measurable and this fact will be used to examine the structure of clause whose base is the main verb of the sentence. According to Halliday's theory, 
transitivity contains different processes which are differentiated on the fact that whether actions, speech, states of mind or states of being are expressed through them.

According to this theory the following kinds of process are identified:

1. Material processes

2. Relational processes

3. Mental processes.

Material processes of transitivity include the processes of doing, generally physiological and material actions. Halliday entitles the clauses which contain these processes, action clauses in which it is made clear that someone or something does some material action or some entity performs some action to some other thing or entity. These processes can be investigated by asking what did $x$ do? Material processes include usually two crucial participants: Actor and Goal. The first one is the doer of some action and the second one is the thing are person which gets affected by the action or process.

Mental processes include mental reactions such as perception, cognition, desire and affection. These processes can also be called the sensing processes. These processes can be investigated by asking the question what do we think/feel/know about $x$ ? Mental processes basically have two participants: the Senser and the Phenomenon. The senser is always a conscious being who can feel, think or see. Phenomenon is the thing or entity which is felt or perceived by the senser. Relational processes are used to construct the relationships of being and having between two participants. Relational processes are classified into two different kinds; identifying and the attributive relational process. The relational process which is used to identify and define the entity is called identifying relational process. It includes two participants; one is the Token is the participant which is identified by the value and value is used to describe the Token. And the second type of the relational process is used to describe the entities. The participants which are related to it include the Carrier and the Attribute. It can 
be said that "the $\mathrm{x}$ (recognized by the Carrier) is an element of the group $\mathrm{y}$ (identified by the Attribute)".

There are also three other additional process kinds that include the trait features of each of the three main processes. Behavioural processes exist between the Material and Mental processes that illustrate the external expression of inside working and produce physical and mental behaviours such as weep, laugh, smile, dream... Behavioural processes typically include one participant who is usually a conscious being and is labelled with the name of the Behaver. Between Mental and Relational processes lie Verbal processes, which are the representation of the act of saying and its synonyms (call, ask, tell etc). Verbal processes include usually three participants: the Sayer is a conscious being and is someone who controls the verbal process (speaks or utters something); the Receiver is the person who listens or for whom the verbal process is performed; and the Verbiage is the nominal declaration of the verbal process. And between Relational and Material processes exist the Existential processes that express state of being, existing, and happening. Existential processes usually include the verb be or its synonyms such as exist, arise, occur. Existential process includes only one participant which is called existent and it follows the "there is/are" series.

Table 1. Examples of different process types from "The Happy Prince"

\begin{tabular}{|c|c|}
\hline $\begin{array}{c}\text { Process } \\
\text { Type }\end{array}$ & $\begin{array}{l}\text { Examples } \\
\text { (Participants are underlined; Process are in bold; Circumstances }\end{array}$ \\
\hline Material & $\underline{\text { He in Italics) }}$ \\
\hline Behavioural & $\underline{\text { The prince was weeping. }}$ \\
\hline Mental & $\underline{\text { The Swallow thought. }}$ \\
\hline Verbal & $\underline{\text { 'Who are you?' asked the Swallow. }}$ \\
\hline Relational & 'I am $\underline{\text { the Happy Prince.' }}$ \\
\hline
\end{tabular}


Halliday and Matthiessen (1976) give no priority to any one process kind over the other kind of process so they represent the relationship among transitivity processes in a way that allows us to interpret and create our ideational meanings of the world and helps us to understand what is happening around us. Transitivity processes also prove to be useful in discovering and revealing the participants included; how the speaker/writer establishes himself in relationship with the others, and it also reveals the fact that whether they are active or passive in the communication creating process.

After a brief introduction and theoretical background of the transitivity and its processes from

Halliday's systemic functional grammar, the researcher has also used the framework of transitivity analysis presented by Halliday to elaborate linguistic features of the text which are used to describe the characters their status in the text and different themes and meanings of the text created by the writer in a literary discourse, a short story titled "The Happy

Prince”. The Happy Prince and Other Tales also sometimes called The Happy Prince and Other Stories is an accumulation of stories for kids by Oscar Wilde initially distributed in May 1888. It is most celebrated for The Happy Prince, the short story of a metal statue who gets to know a transitory swallow bird. Together, they convey bliss to others, in life and in addition in death.

The story passes on an admiration for generosity, sympathy, love and majesty.

Significance of the study

The study will be important in emphasizing literature as a critical way through which language is subjugated to construct actions and craft characters. It is apt to emphasize the range 
of transitivity analysis in establishing a significant knowledge of the character sketch in literary passage, specially a short story about a statue of a prince. The study will also be important for the teachers and learners in teaching and learning literature. Both the teachers and students can find this research useful for understanding various literary writings which usually contain the implicit meanings.

Research question.

How transitivity analysis helps in interpreting the characters construction in the short story "The Happy Prince"?

\section{Methodology}

In this study the portrayal of the characters has been created through a close textual analysis of the selected text which is taken from the popular short story "The Happy Prince" produced by a famous writer Oscar Wilde. Transitivity analysis was used as the tool in the study which makes up the expreriantial metafunction under M.A.K Halliday's Systemic Functional Grammar (SFG). In the first step of the analysis, the researcher divided the text of the short story into clauses; because the basic unit of analysis in SFG is a clause. In the second step the clauses were numbered in the order they were in the story. In the next step, each clause wass devided into "Participants", "Processes" and circumstances. Labels have been conferred to the different types of processes. Data has been described and discussed qualitatively.

Introduction to the Writer

Born on October 16, 1854 in Dublin, creator, writer and artist Oscar Wilde was a well known scholarly figure in late Victorian England, known for his splendid mind, flashy style and scandalous detainment for homosexuality. Subsequent to moving on from Oxford 
University, he addressed as a writer, craftsmanship commentator and a main defender of the standards of aestheticism. In 1891, he distributed The Picture of Dorian Gray, his solitary novel which was panned as indecent by Victorian pundits, however is currently viewed as one of his most striking works. As a screenwriter, a significant number of Wilde's plays were generally welcomed including his ironical comedies Lady Windermere's Fan (1892), A Woman of No Importance (1893), An Ideal Husband (1895) and The Importance of Being Earnest (1895), his most well known play. Flighty in his written work and life, Wilde's undertaking with a young fellow prompted his capture on charges of "net profanity" in 1895 . He was detained for a long time and passed on in destitution three years after his discharge at 46 years old.

Starting in 1888, while he was all the while filling in as proofreader of Lady's World, Wilde entered a seven-year time of irate innovativeness, amid which he delivered almost the greater part of his extraordinary abstract works. In 1888, seven years after he composed Poems, Wilde distributed The Happy Prince and Other Tales, an accumulation of youngsters' accounts. In 1891, he distributed Intentions, an article accumulation contending the precepts of aestheticism, and that same year, he distributed his sole novel, The Picture of Dorian

Gray. The novel is a wake up call about a wonderful young fellow, Dorian Gray, who wishes (and gets his desire) that his picture ages while he stays energetic and carries on with an existence of wrongdoing and joy.

In spite of the fact that the novel is presently loved as an incredible and great work, at the time pundits were insulted by the book's evident absence of ethical quality. Wilde passionately guarded himself in an introduction to the novel, considered one of the immense demonstrations of aestheticism, in which he stated, "a moral sensitivity in a craftsman is an unforgivable idiosyncrasy of style" and "bad habit and excellence are to the craftsman materials for a workmanship." 
A Brief Introduction to the short story The Happy Prince

The Happy Prince is a short story written by Oscar Wilde, which was published in 1888. This story is about a prince who had lived a happy and luxury life. His palace was very large and was at an isolated place. When he died, he was changed into a statue which was fixed at the top of a hill in a town. He was here to see the sufferings, troubles, sorrows and heartbreaks of the people of the town. A little bird, swallow sought shelter in the feet of the statue when he was on his way to Egypt with his friends. He became the messenger of the statue of the prince and helped the suffering people of the town. On the request of the prince, he brings the people the jewels from his waist and his eyes and the gold strips which decorated his body. The swallow began to love the statue and decided to live with him forever because the prince was blind now. Heavy rain started and was followed by snow. It became cold and the swallow caught cold and died in the feet of statue. The statue now being blind and had been deprived of its gold and jewels lost its lustre and brightness. His heart was broken and his statue along with the dead body of swallow was thrown on the heap of dust. God pleased on his kindness and they entered into the paradise. The swallow would fly in the bliss garden and the statue of prince would be placed on the hill top in the Heaven.

Transitivity analyses of the text of the short story titled "The Happy Prince"

The researcher applied the system of transitivity analysis on the text of a short story “The Happy Prince” by Oscar Wilde taken from "The young King and other stories” Essex, Penguin Books, 2000. The transitivity analysis of text containing the results is summarized in Table 1 below. 
Table 2 Transitivity Analysis of "The Happy Prince"

\begin{tabular}{|c|c|c|c|}
\hline \multicolumn{4}{|c|}{ Transitivity } \\
\hline Process type & Frequency & $\%$ age & \\
\hline material & 135 & $43.41 \%$ & \\
\hline mental & 35 & $11.25 \%$ & \\
\hline verbal & 53 & $17.04 \%$ & \\
\hline behavioural & 14 & $04.50 \%$ & \\
\hline existential & 11 & $03.54 \%$ & \\
\hline relational: attributive & 55 & $17.68 \%$ & $20.26 \%$ \\
\hline relational: identifying & 03 & $0.97 \%$ & \\
\hline relational: possessive & 05 & $01.61 \%$ & \\
\hline total no. of processes & 311 & & \\
\hline
\end{tabular}

Critical Discussion of the findings

As the transitivity analysis shows, the text consists of three hundred and eleven (311) processes. This number is the collection of the six types of processes which have been defined by Halliday and Matthiessen (2004). The predominant processes out of six are three i.e. material processes $(43.41 \%)$, relational processes $(20.26 \%)$ and verbal processes $(17.04 \%)$. Mental processes have also appeared with less dominance with the percentage of $11.25 \%$. However, the other two processes i.e. behavioural and existential have appeared with very low prominence in the text with their different proportions $4.50 \%$ and $3.54 \%$ respectively.

Overmaterialization has been shown in the text through the predominant use of the proportion of the material processes (135 out of 311 with the percentage of 43.41). The results have also been shown in the chart 1 . 
Chart 1 Transitivity Analysis of "The Happy Prince"

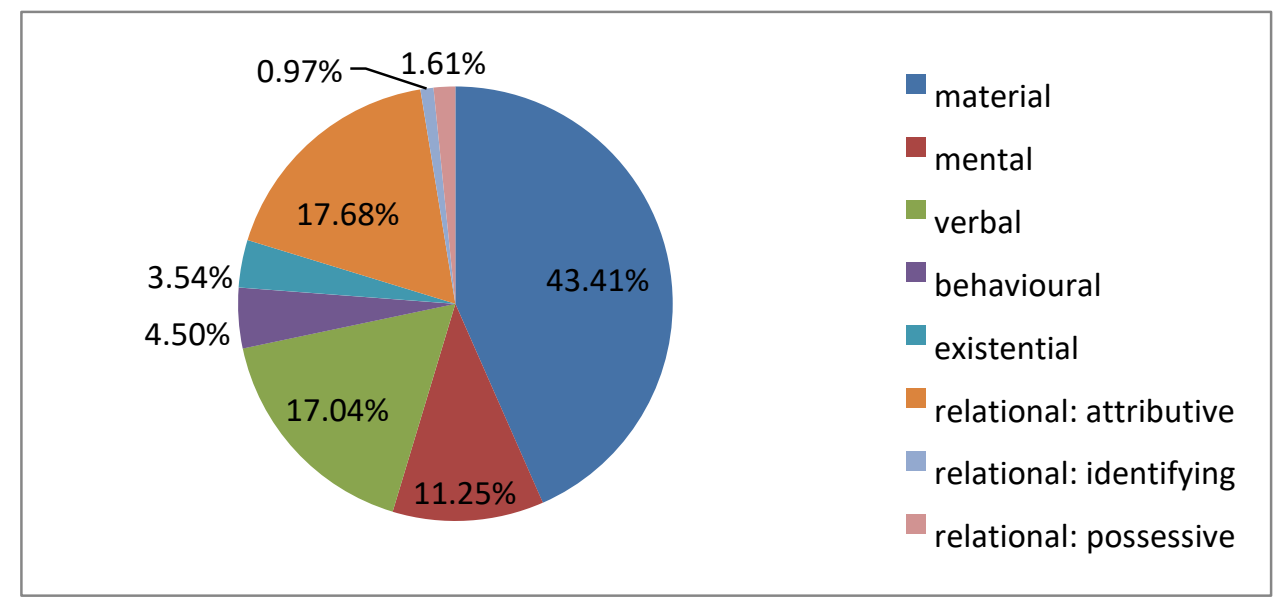

This indicates that the whole text is centrally concerned with actions and events and the participants who carry them out. However, the proportion of material processes to other process types is highest in the Text so the text, then, is predominantly about tangible, physical and concrete actions. The keen analysis shows that the most of the material processes in the story are related with the little bird namely Swallow. By analysing his predominant role as an actor shows that most of the material acts have been carried out by the swallow bird. As the examples show:

One night a little Swallow flew alone over the city

I will stay there

He landed between the feet of the Happy Prince

So the Swallow took the great red jewel from the prince's waist and flew away with it over the roofs of the town. He passed the palace and heard the sound of dancing.

The Swallow passed over the river and flew and flew. At last he came to the poor little house

I am going to the House of Death.' He kissed the prince, and fell down dead at his feet 
The material processes related with the little bird show that the swallow bird is an active character and performs most of the actions and activities for the sake of poor people on the request of the statue of the Prince. Very rare material processes are related with the statue of the prince as an actor. This investigation shows that the statue of the prince is a passive character and cannot perform any action.

The analysis of the text exposed 35 mental processes, making $11.25 \%$. In the text, most of mental processes have been performed by the two main characters the statue of the prince and little swallow bird. The analysis discovered that 17 out of 35 mental processes were taken by the swallow bird and 6 mental processes by the statue of the prince. The conferring of the mental processes to the inhuman objects (the bird and the statue) shows that they are sensing like human beings. The processes like (see, think, decide, feel, forget, love, hear, know) show that the bird and the inanimate statue are sensing like human beings. The mental processes show the kind, loving, caring nature of the main characters of the short story. The characters in the story as phenomena are the society where poor people live. The poverty of the society has been investigated through the participants as phenomena.

Verbal processes with the frequency of 53 out of 311 with the ratio of $17.04 \%$ have also been revealed through the transitivity analysis of the text. Here, as almost all the processes are declarative, the Sayer roles are carried out by the two main characters the statue and the bird as sayer in "The Happy Prince". They have been personified by the writer through the use of verbal processes (said, told, asked) associated with them. Analysing the roles of sayer and Receiver Participants, the most of the part of the text of the short story consists of dialogue form as the conversation most of the time takes place between the statue of the prince and the bird.

'Little Swallow, little Swallow,' said the prince, 'please will you stay with me for one more night?’ 
'My friends are waiting for me,' answered the Swallow.

'Far away across the city,' said the prince,

'I will wait with you for one more night,' said the Swallow kindly. 'What shall I take to him?'

'Take him one of my eyes,' said the prince. 'They are made of beautiful blue stones from India. The young man can sell it and buy wood and food. He can finish his story.' 'Take out your eye, dear prince?' said the Swallow. 'I cannot do that!' And he began to cry.

'Do it!' said the prince.

Most of the processes are in direct speeches and in the declarative forms. The analysis of the nature of verbiage shows that most of the declarative statements are very polite and shows the kind, loving and generous nature of the both characters.

It has been investigated through the transitivity analysis that the text has 63 relational processes including (55) attributive, (05) identifying, and (03) possessive. This proportion of Relational processes in the text stands for $20.26 \%$. The distributive relational processes have been used to create descriptions about the characters and other objects in the story. This indicates that Text is descriptive which is just as much concerned with defining as describing participants.

Table 3 Circumstances in "The Happy Prince"

\begin{tabular}{|l|c|c|}
\hline \multicolumn{2}{|l|}{ Circumstances } & $\%$ age \\
\hline Type & Frequency & $52.00 \%$ \\
\hline Location: place & 95 & $20.00 \%$ \\
\hline Location: time & 37 & $2.29 \%$ \\
\hline extent & 04 & \\
\hline
\end{tabular}




\begin{tabular}{|l|c|c|}
\hline Accompaniment & 15 & $8.57 \%$ \\
\hline manner & 15 & $8.00 \%$ \\
\hline Cause & 11 & $5.71 \%$ \\
\hline behalf & 04 & $1.14 \%$ \\
\hline Means & 02 & $100 \%$ \\
\hline total & 183 & \\
\hline no. of ranking clauses & 308 & \\
\hline
\end{tabular}

Table 3 presents numbers for each type of Circumstantial element in the text. As this table shows, the Text has a high number of Circumstances in proportion to its length. Part of the function of these circumstantial elements appears to be to deflect arguability from certain participants.

The table shows that the circumstance of location including place and time are predominant in the text with the frequency of $52 \%$ and $20 \%$ respectively. The analysis of the circumstances has been illustrated more precisely through the chart 2.2.

Chart 2 circumstances in "The Happy Prince"

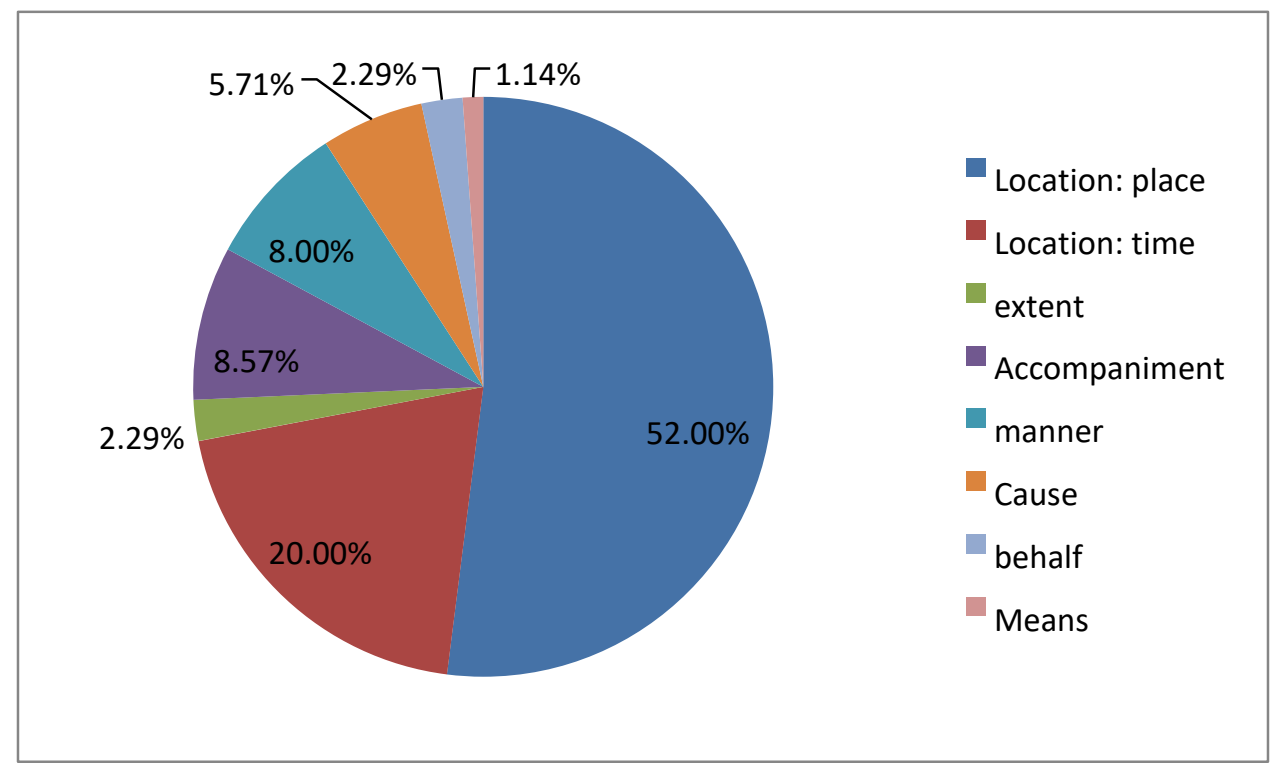


Circumstances of time and place show how the writer has depicted the characters in the story in the context of place and time. These circumstances have been used to establish the setting of the events and actions of the story. The writer has used to the circumstances to create the impression of when and where the participants have been involved in the setting of the story.

One night a little Swallow flew alone over the city. The other Swallows were all in Egypt now. 'Where can I stay tonight?' he thought. Then he saw the statue. 'I will stay there,' he thought. 'It is high up, so there is plenty of fresh air.'

He landed between the feet of the Happy Prince. 'I have a golden bedroom!' he thought.

The following passage contains three circumstances of time i.e. one night, now, tonight and five circumstances of place i.e. over the city, in Egypt, where, there, between the feet of the Happy Prince. These circumstances of time and place have been used to create the overall setting including time (scene at night) and place (between the feet of the statue of the happy prince).

In the same way the circumstances of manner and cause have also been used to create and depict the characters of the story through elaborating the way how the participants act and behave in the text and what is the cause of their action or behaviours.

She is making a dress for one of the queen's ladies, for a dance in the palace.

'That is because you have done a good thing,' said the Swallow kindly. he cried happily.

First two lines show the circumstances of the cause and the next two lines show the circumstance of manner. Another certain dominant circumstance which has been discovered through the analysis of the text is the circumstance of accompaniment. It elaborates the 
relationship and coordination of the participants. What a participant does in the company of whom?

'please will you stay with me for one more night?' and flew down with it.

Some other circumstance have also been used, however having very low prominence in the context i.e. extent, behalf and means circumstances with ignorable figures in the text. Conclusion

Halliday has presented the Systemic Functional Linguistic (SFL) Analysis theory. The present study investigated the phenomenon how the writer established different variety of characters in the story with the choice of linguistic features. To achieve this purpose the data were taken from the famous short story titled "The Happy Prince" written by an Irish writer Oscar Wilde. The researcher applied the systemic functional linguistic theory presented by Halliday for transitivity analysis of the text. The text was manually analysed by the researcher. All the processes, participants and circumstances were recognized from the whole text. They were arranged in the form of tables and charts. The results were discussed in the qualitative method of research. The results show that three types of process i.e. material $(43.41 \%)$, relational $(20.26 \%)$ and verbal $(17.04 \%)$ were predominant in the whole text. The highest dominance of the material process shows that the writer has created dynamic and tangible actions in the text. Similarly circumstances of location i.e. place (52\%) and time (20\%) were dominant in the whole text. The significance of the study was also discussed in the educational perspective. 


\section{References}

Koussouhon, L. A. (2015). Exploring Ideational Metafunction in Helon Habila's Oil on Water: A re-evaluation and redefinition of African Women's Personality and Identity through Literature. International Journal of Applied Linguistics \& English Literature .

Zahoor, M., \& Janjua, F. (2016). Character Construction In Tributive Songs: Transitivity Analysis Of The Song “I Am Malala”. Trames .

Halliday, M. A. K. (1971) Linguistic function and literary style: an inquiry into the language of

William Golding's The Inheritors. In S. Chatman, ed. Literary style: a symposium, 330368. New York: Oxford University Press.

Yaghoobi, M. (2009) “A critical discourse analysis of the selected Iranian and American printed media on the representation of Hizbullah-Isreal Wa"r. Journal of Intercultural Communication

Mwinlaaru, I. N. (2012) “Transitivity and narrative viewpoint in Ngugi wa Thiong'o's Weep Not, Child”. In Dora F. Edu Buandoh and Anita B. Appartaim, eds. Between language and literature: a festschrift for Professor Kofi Edu Yankson, 354-370. Cape Coast: Cape Coast University Press.

Azar, A. S. and N. S. Yazdchi (2012) "A stylistic analysis of "Maria" in "Clay": the character in James Joyce's short story". Journal of Basic and Applied Scientific Research 2, 2, $1050-1055$.

Bloor, T., \& Bloor, M. (2004). The Functional Analysis of English (2nd ed.). London: Arnold.

Gee, J. P. (2005). An Introduction to Discourse Analysis: Theory and Method. London: Routledge. 
Kroger, R. O., \& Wood, L. A. (2000). Doing Discourse Analysis: Method for Studying Action in Talk and Text. California: Sage Publications, Inc.

Halliday, A. K. (1985). An Introduction to Functional Grammar (2nd ed.). London, Melbourne, Auckland: Edward Arnold.

Fairclough, N. (1989). Language and Power. New York: Longman Group UK Limited.

Fairclough, N. (2001). Critical Discourse Analysis as a Method in Social Scientific Research. In Wodak, R., \& Meyer, M. (Eds), Methods of Critical Discourse Analysis (pp. 121138). London: Sage Publications.

Fowler, R. (1986). Linguistic Criticism. Oxford: Oxford University Press.

Simpson, P. (1993). Language, Ideology and Point of View. New York: Routledge.

Fairclough, N. (2003). Analysing Discourse: Textual Analysis for Social Research. London: Routledge Taylor \& Francis Group.

Wodak, R. (2001). What CDA Is About - a Summary of Its History, Important Concepts and Its Development. In Ruth

Mehmood, Asad, at al. (2014). Transitivity Analysis: Representation of Love in Wilde's The Nightingale And The Rose. Pakistan: University of Sargodha.

Halliday, M. A. K., \& Matthiessen, C. M. (2004). An Introduction to Functional Grammar (3rd ed.). London: Arnold.

Eggins, S. (2004). An Introduction to Systemic Functional Linguistics. London: Pinter.

Kress, G. (Ed.). (1976). Halliday: System and Function in Language: Selected Papers. London: Oxford University Press. 